\title{
Effect of mixing Mach number and mixing efficiency on the preliminary cycle design of mixed high-BPR turbofans
}

\author{
Bjorn Cleton, Eduardo Anselmi*, Alvise Pellegrini, Vassilios Pachidis, Panagiotis \\ Laskaridis
}

Propulsion Engineering Centre, Cranfield University, Bedfordshire, MK43 0AL, United Kingdom

* Corresponding author. Email: e.a.anselmipalma@cranfield.ac.uk Tel. +44(0) 1234 758167

\begin{abstract}
This article presents the implementation of an updated analytical flow mixing model in a state-of-the-art, non-dimensional gas turbine cycle performance simulation and optimisation tool. The model considers three separate streams in the mixer, each expanding through its own 'virtual' nozzle. The use of three streams, compared to one single stream, allows for a more realistic simulation of a mixed exhaust gas turbine. This approach is used in a parametric study to assess the effect of the choice of mixing efficiency and mixer inlet Mach number on the preliminary design of mixed-exhaust, high-bypass ratio turbofan engines. It was found that in terms of best thermal performance, a trade-off exists between mixer inlet Mach number and mixer effectiveness. The findings of this research establish some useful guidelines for the accurate selection of these two parameters to achieve robust cycle designs.
\end{abstract}

Keywords: mixing efficiency, parametric study, mixer inlet Mach number, theoretical thrust gain

\section{Nomenclature}

$\begin{array}{cl}\text { BPR } & \text { Bypass Ratio [-] } \\ \text { FPR } & \text { Fan Pressure Ratio [-] } \\ \text { FPR }_{\mathrm{op}} & \text { Fan Pressure Ratio optimum [-] } \\ \text { OPR } & \text { Overall Pressure Ratio [-] } \\ \text { CET } & \text { Combustor Entry Temperature [K] } \\ \text { TET } & \text { Turbine Entry Temperature [K] } \\ \text { LPT } & \text { Low Pressure Turbine [-] } \\ \text { SpT } & \text { Specific Thrust [-] } \\ \text { TR } & \text { Temperature Ratio between hot and cold stream [-] } \\ \mathrm{P}_{\mathrm{c}} & \text { Total pressure mixer inlet pressure cold stream }[\mathrm{kPa}] \\ \mathrm{P}_{\mathrm{h}} & \text { Total pressure mixer inlet pressure hot stream }[\mathrm{kPa}] \\ \mathrm{F}_{\mathrm{N}} & \text { Thrust [N] } \\ \eta_{m i x} & \text { Mixing efficiency [-] } \\ \mathrm{T}_{\mathrm{c}} & \text { Temperature mixer inlet cold stream }[\mathrm{K}] \\ \mathrm{T}_{\mathrm{h}} & \text { Temperature mixer inlet hot stream [K] } \\ \mathrm{M}_{\mathrm{h}} & \text { Mach number inlet mixer hot stream [-] } \\ \mathrm{W}_{\mathrm{c}} & \text { Mass flow mixer inlet cold stream }[\mathrm{kg} / \mathrm{s}] \\ \mathrm{W}_{\mathrm{h}} & \text { Mass flow mixer inlet hot stream }[\mathrm{kg} / \mathrm{s}] \\ \mathrm{M}_{\mathrm{c}} & \text { Mach number inlet mixer hot stream [-] }\end{array}$




$\begin{array}{cl}P & \begin{array}{l}\text { Perimeter of line contact between both flows at the mixer chamber } \\ \text { entry [m] }\end{array} \\ L_{m c} & \text { Length of the mixing chamber [m] } \\ D_{m c} & \text { Hydraulic diameter of the mixing chamber }[\mathrm{m}] \\ C_{D} & \text { Nozzle discharge coefficient [-] } \\ \gamma_{c} & \text { Heat capacity ratio cold stream [-] } \\ \gamma_{h} & \text { Heat capacity ratio hot stream [-] }\end{array}$

\section{Introduction}

Mixed exhausts have commonly been used in gas turbines for military purposes, as well as in a wide range of civil aero gas turbines, such as the CFM56-5C, RB211-524G/H, RB211535E4, and Trent $700^{[1]}$. The foundation of this type of gas turbine comes from research performed in the $1960 \mathrm{~s}$ by Frost ${ }^{[2]}$, Pearson ${ }^{[3]}$ and Hartman ${ }^{[4]}$. At the same time,

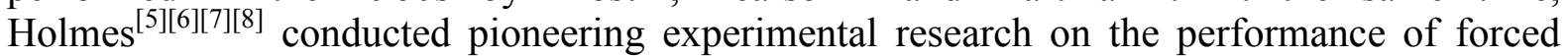
mixed-exhaust turbofans. Early work in this field from the National Aeronautics and Space Administration (NASA) is dated in the $1970 \mathrm{~s}^{[9][10]}$, however it was in the 1980s when studies were conducted into different mixer types, as well as the performance benefits of these configurations (e.g., Kuchar and the $E^{3}$ program) ${ }^{[11][12][13][14][15]}$. Since the 1990s, published research has been primarily focused on understanding the flow behaviour (eddy losses) within the flow stream (using CFD and various experimental arrangements) ${ }^{[16][17][18][19][20][21]}$. During all these years, identifying potential benefits in performance, when comparing mixedexhaust turbofans against separate-exhaust, has always been of interest.

The underlying idea is that exhaust mixing enables the core exhaust stream (hot/fast) to transfer energy to the bypass exhaust flow (cold/slow), without the use of a heat exchanger or mechanical means. The goal is to increase thrust at design point, but also at other operating points. This is done by increasing the temperature of the bypass stream, therefore increasing the average exit velocity of the flow through the common nozzle ${ }^{[20]}$.

The thrust increase achieved by the mixed exhaust is commonly referred to as theoretical thrust gain. Previous research has shown that the theoretical thrust gain that can be achieved through the use of a mixer can be between $2-3 \%$ in ideal conditions when comparing it against the same configuration but with a separate exhaust system ${ }^{[2]}$. The amount of achievable theoretical thrust gain highly dependents on engine design parameters for fixed thrust requirements. These cycle design parameter are: fan pressure ratio (FPR), overall pressure ratio (OPR), bypass ratio (BPR), combustor entry temperature (CET), turbine entry temperature (TET) and specific thrust (SpT).

Previous research ${ }^{[22]}$ has shown the importance of choosing the correct cycle design parameters. However, it has not fully shown the influence of mixing efficiency and axial Mach number at the mixer inlet on the six other parameters mentioned previously. More importantly, a complete analytical method of how to model mixing efficiency correctly in a non-dimensional (0D) cycle analysis code has not been presented up to now in the public domain. In many instances, mixing efficiency is not considered. When it is considered, users are driven to specify either fixed percentages of theoretical thrust gain, or fixed fractions for each mixing stream. In both cases, industrial experience or experimental insight is required which may not be available or practical in a research environment. 
This manuscript discusses how to model a mixed-exhaust, high-BPR turbofan engine while taking mixing efficiency into account. The scope of this parametric study focuses on the interdependence of the mixing efficiency and the axial Mach number at the mixer inlet, and their relationship with the ratio of mixer inlet total pressures at design point. The method and results presented are important from a scientific and research point of view, as traditionally, when designing a theoretical mixed-exhaust turbofan cycle, those two parameters are chosen almost arbitrarily from previous experience or based on outdated literature.

\section{Theoretical background}

In a mixed-exhaust turbofan engine, the core stream is mixed with the bypass prior to ejection through a common nozzle. In a civil turbofan engine, with a medium to high BPR (i.e. BPR 4 $\sim 6$ ), a significant temperature ratio exists between the core and bypass stream, where for example, at cruise the core stream can be as much as 2.5-3 times hotter than the bypass stream. The core stream is expanded to a relatively high velocity through a core nozzle. The high velocity of the core is detrimental to propulsive efficiency, as well as a major source of noise. The residual heat in the core exhaust is an unavoidable consequence of a practical Brayton cycle, as well as a function of the losses in the system. In a mixed-flow engine, the waste heat is partially transferred to the bypass stream, which for a realistic cycle can lead to a reduction of energy needed to be transferred by the shaft and therefore, reduced losses across the fan and low-pressure turbine.

In a separate-flow turbofan engine, for a given fuel flow, BPR and fan mass flow rate, there exists an optimum bypass-to-core nozzle jet velocity ratio which yields the maximum gross thrust. The ratio of bypass-to-core nozzle jet velocity is approximately equal to the transfer efficiency ${ }^{[22]}$ and can be proven analytically for a simplified turbofan ignoring the effect of duct losses. For an equivalent optimum jet velocity in a mixed-flow engine, it has been found that the jet velocity ratio should be determined in the mixing plane and that this corresponds to the hot stream (core) to cold stream (bypass) ratio of total pressures. The optimum ratio of total pressures in the mixing plane is a function of the fundamental pressure losses in the mixing plane, the temperature ratio in the mixing plane and the transfer efficiency.

Different authors ${ }^{[2][3][23][24]}$ have proven that a ratio of mixer inlet total pressures that is approximately equal to unity typically yields the highest thrust for a given fuel flow. Pearson $^{[3]}$ suggested that if a mixer is modelled as an ideal heat exchanger, a thrust gain (when compared with a separate-flow exhaust engine) can be obtained at a ratio of total pressures slightly higher than 1.0. This would occur as heat from the core stream would be transferred to the higher pressure bypass stream resulting in a useful energy gain. Typically, the condition of equal total pressures in the mixing plane is imposed in order not to incur excessive off-design pressure losses in the mixing process and so to improve mixer operability across the operating envelope. Rayee et al. ${ }^{[25]}$ demonstrated that the $\mathrm{FPR}_{\text {op }}$ for a mixed turbofan is fixed by this condition.

Apart from the total pressure ratio, it is commonly quoted that the degree of gross thrust gain is also a function of temperature ratio, mixer inlet Mach number and BPR. Figure 1, adapted from Rayee et al. ${ }^{[25]}$, shows for example that gross thrust gain from mixing is increased as the temperature ratio (TR) between the two streams is increased at the mixing chamber inlet (a similar graph can be also found in ${ }^{[26]}$ ). Also of interest is the fact that the gain in gross thrust peaks at low BPR while at higher BPR it is substantially less. This gives a clue as to why mixed-exhaust engines are no longer attractive for ultra-high BPR engine applications. 


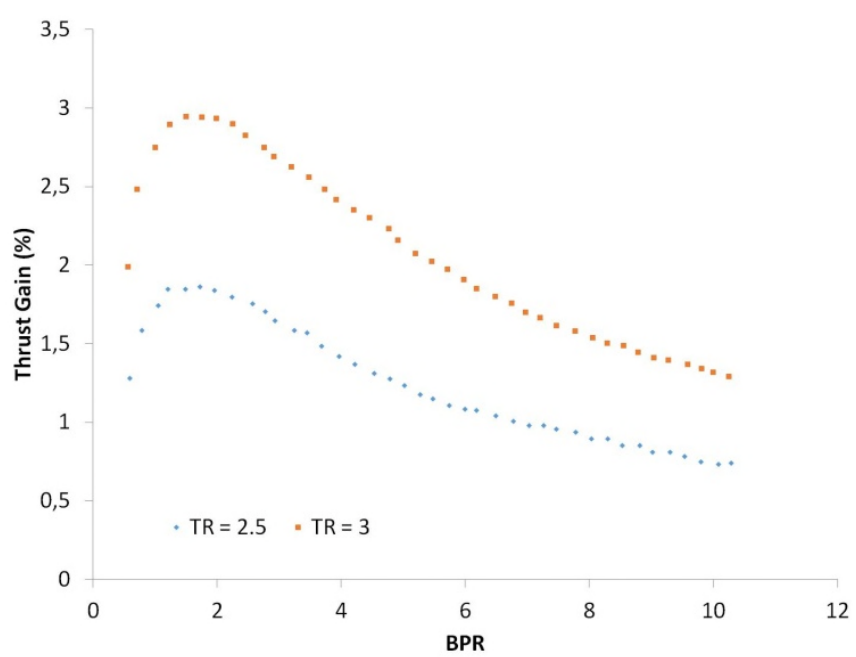

Figure 1 - Gain in Gross Thrust as a function of TR and BPR (75\% mixing efficiency, $10 \%$ chute pressure losses, inlet Mach number 0.4, $\left(P_{h}=P_{c}\right)^{[25]}$

The selection of the mixer inlet Mach number is of importance. Mixing occurring at low Mach number would result in increased mixing efficiency and reduced pressure losses. The minimum value was pointed out by Hartman ${ }^{[4]}$, quoting the range of $0.2-0.25$ to avoid losses "due to deceleration of the hot stream beyond the turbine". However, there are additional considerations, for example geometrical limits in the mixer frontal area, which cannot be exceeded. The total geometric entry area should fit within the dimensions of the bypass duct (upper limit) and the low pressure turbine (lower limit). In fact, the lowest mixing Mach number could be selected by imposing a fixed frontal area of mixer inlet or nozzle inlet ${ }^{[25]}$. Mixing occurring at very high Mach numbers would be detrimental as the time spent for both streams in the mixing chamber is less, affecting the energy transfer process and increasing pressure losses.

Before introducing the metrics for good mixer performance, it should be mentioned that a fifth parameter is also linked with the gross thrust gain of mixed engines; this is the nozzle pressure ratio. This is a factor that is mostly relevant to off-design analyses, and hence out of scope in this design-point parametric study.

\subsection{Mixer fundamentals}

Mixer performance can be assessed on the basis of two parameters of interest; mixing efficiency and mixer pressure loss. Commonly, mixing efficiency is defined as the ratio of actual thrust gain due to mixing, to the theoretical thrust gain for a fully mixed flow (see equation $(1)^{[2]}$ ). This definition includes "increase in thrust due to thermodynamic mixing and the decrease in thrust due to loss in momentum (pressure loss) ${ }^{[11]}$ ". This loss in momentum is called "fundamental loss" and it does not reflect the aerodynamic friction and flow turning loss of the mixer lobes.

$$
\eta_{\text {mix }}=\frac{\mathrm{F}_{\mathrm{N}_{\text {partial-mix }}}-\mathrm{F}_{\mathrm{N}_{\text {separate }}}}{\mathrm{F}_{\mathrm{N}_{\text {ideal-mix }}}-\mathrm{F}_{\mathrm{N}_{\text {separate }}}}
$$

Mixer pressure loss is the parameter which represents the aerodynamic friction (or skin friction) and turbulence of the flow in the mixing chamber. In practice, this loss comprises 
phenomena such as; i) the viscous effect of the flow over the surfaces of the mixer lobes, ii) the drag effect of the flow velocity field encountering the installed chute (lobes and pylon) in the fan duct and finally, iii) the viscous effects over the inner walls of the mixing chamber, the jet pipe and the nozzle. These losses are experimentally not easy to determine. These two performance metrics of the mixer chamber require complex and advanced techniques to be computed or measured.

Although the mixing efficiency definition given by equation Eq. 1 is widely used, it should be emphasized that this definition is not the only one available. This thrust-based definition is built on the assumption that a specified proportion of the theoretical mixing gain could be achieved. There is also the concept of thermal mixing efficiency, which is defined in terms of the mass-weighted, square root values of the relevant temperatures ${ }^{[12]}$. As it can be seen in Eq. 2, it is a metric which combines experimental measurements of the total temperature at the actual nozzle exit stream and the calculation of the unmixed and fully mixed stream temperatures at mixer inlet conditions.

$$
\eta_{\text {eff }}=\frac{\left(W_{c}+W_{h}\right)\left(T_{\text {actual mix }}\right)^{1 / 2}-\left[W_{c}\left(T_{c}\right)^{1 / 2}+W_{h}\left(T_{h}\right)^{1 / 2}\right]}{\left(W_{c}+W_{h}\right)\left(T_{\text {ideal mix }}\right)^{1 / 2}-\left[W_{c}\left(T_{c}\right)^{1 / 2}+W_{h}\left(T_{h}\right)^{1 / 2}\right]}
$$

In reality, when actual exit stream values are integrated from experimentation, the mixing efficiency becomes the mixing function " $\mathrm{K}_{4}$ " from Frost ${ }^{[2]}$, which can be linked with the simplified expression of Eq. 1. The next section provides a deeper discussion on mixing models for completeness.

\subsection{Mixing models}

Current publications about mixed-flow engines have their foundations in classical low-BPR engine research from the $1960 \mathrm{~s}$, such as Pearson in $1962^{[3]}$, and Frost in $1966^{[2]}$, and subsequent developments ${ }^{[16][19][27]}$. In general, it could be said that these are methods for computing mixing in a constant area duct, assuming adiabatic and inviscid flow evolution. In these methods, the condition of equal static pressures in both streams at chute exit requires an iterative solution of energy momentum and mass flow balance. To maximize the potential benefits of mixing, optimum mixing conditions need to be expressed in terms of the ratio of total pressures at design point, and either the Mach number of the cold stream, or the Mach number of the hot stream at design point (Sanghi et al. ${ }^{[28]}$ ).

Two approaches for modelling mixing have been considered. Figure 2 illustrates the confluent or one-stream model, whereas Figure 3 reflects the lobed or three-stream model. In the first approach, the flow at the mixer exit is homogeneous (see Figure 2), whereas in the second one (Figure 3), three separate jets expand through the same nozzle, with only one fully mixed. In Table 1, a summary of the main features for both approaches is shown. It must be recognised that although Wachter and $\mathrm{Kopf}^{[27]}$ have proposed an alternative twostream model, the previous two models in Table 1 are the most popular. 
Please do not include headers and footers

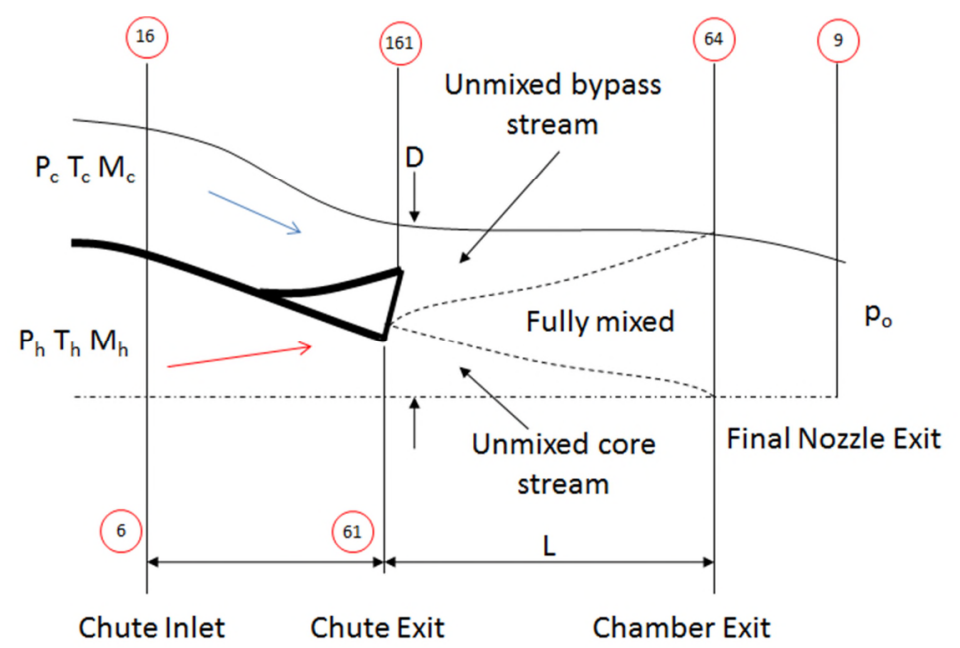

Figure 2 - Confluent mixer or one-stream model adapted from ${ }^{[2]}$

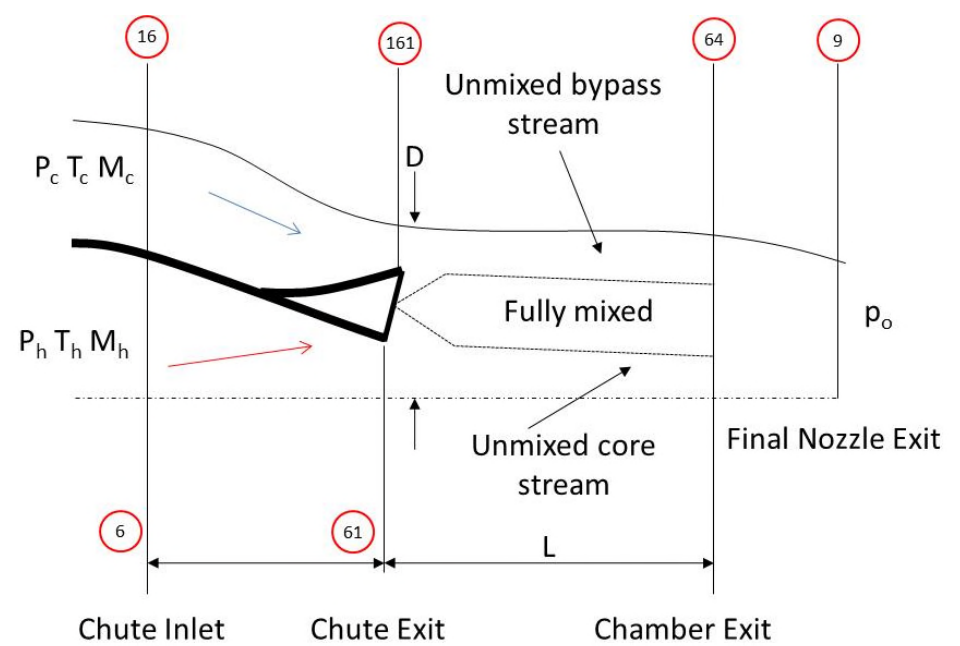

Figure 3 - Lobed mixer or three-stream model adapted from ${ }^{[16]}$

Table 1 - Comparison of the main features between the one-stream and the three-stream models

\section{One-stream model}

Mixing chamber of constant flow area (or confluent mixer)

- Static pressure constant in plane 64

- Total pressure ratio in plane 161 (61) near unity

- One-dimensional axial flow conditions

- Wall friction is ignored

- No mixing occurs in the nozzle 64 - 9

\section{Three-stream model}

Lobed mixing chamber, represented by a control volume for a three-stream exhaust model.

- Static pressure in plane 64 equal for the three streams

- Partial mixing: bypass and core flow are not necessarily affected by the mixing process

- There is a trade-off between mixing effects and pressure losses

- Each stream expands separately through a "multi-stream nozzle" 
Please do not include headers and footers

Mixing efficiency and mixing pressure losses can be inter-related through a 'mixing interface function'. This interface function can be defined for example as per Table 2,

Table 2 - Examples of expressions for the interface function

\begin{tabular}{cc}
\hline Frost $^{[2]}$ & Walsh \& Fletcher $^{[26]}$ \\
\hline$C_{D} \frac{P L_{m c}}{\left(D_{m c}\right)^{2}}(2)$ & $\frac{L_{m c}}{D_{m c}}(3)$ \\
\hline
\end{tabular}

Where;

$P \quad$ Perimeter of line contact between both flows at the mixer chamber entry

$L_{m c} \quad$ Length of the mixing chamber

$D_{m c} \quad$ Hydraulic diameter of the mixing chamber

$C_{D} \quad$ Nozzle discharge coefficient

An example of the correlation between mixing efficiency, pressure losses and the interface function is given in Figure 4.

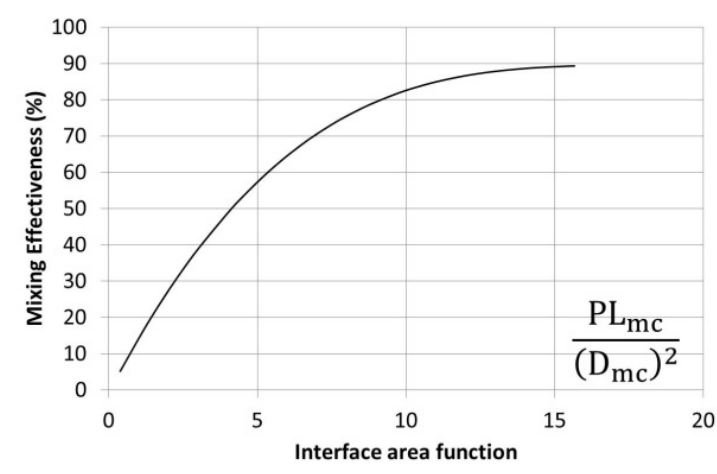

a) Mixing efficiency

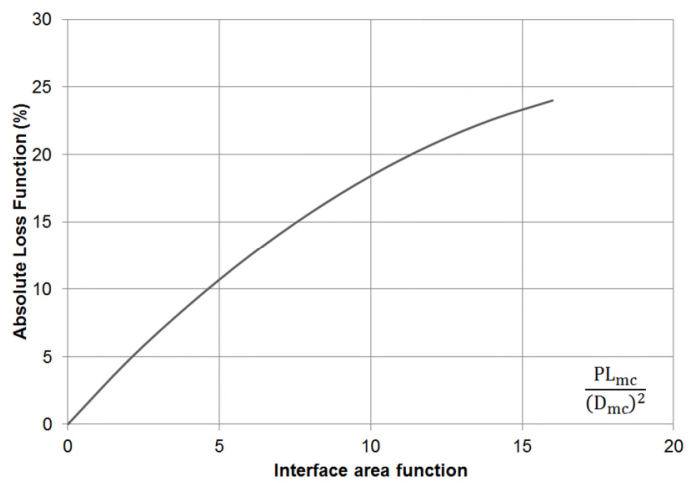

b) Absolute pressure losses

Figure 4 - Correlations of mixing efficiency and pressure losses as a function of the mixer geometry (adapted from Frost ${ }^{[2]}$ when $C_{D}^{0.5}=1$ )

When performing aero engine performance calculations, the mixing efficiency can be related to the specified fraction of each stream which mixes fully. The remaining fraction of each stream is assumed to pass unaffected. Thus, three separate streams pass through a common nozzle. The mixed gross thrust is simply the sum of the thrusts from each stream. Each stream will have a different total pressure, temperature and velocity, and will occupy a different proportion of the common nozzle at different flight conditions.

When relating the mixing efficiency with the mixing fraction of each stream, it should be stressed that the mixing fraction cannot be determined through one-dimensional methods; it can normally be deducted from rig tests as in ${ }^{[27]}$. The mixing fraction can be obtained from exit survey data ${ }^{[29]}$, as weighted areas of known temperatures profiles, or area integration of temperature/velocity contours from CFD models. In this work, the mixer effectiveness and the mixing fraction were simplified by assuming that the percentages of mass flow from each mixing stream were equal.

If the interface function is not used to estimate the pressure losses in the mixer chamber, then an alternative route has to be taken. For example, in a mixer, three mechanisms for pressure losses can be identified: 
- Skin frictional losses due to the viscous effects in the boundary layer,

- Fundamental loss, due to the irreversible mixing process of two gas streams with different properties in the mixer,

- The loss incurred by the mixer (LPT exhaust) because it is a drag in the flow.

To reflect the skin frictional losses of the mixing chamber, friction pressure losses could be calculated as duct losses in the cold and hot streams, before mixing. The fundamental pressure loss is automatically calculated iteratively once the momentum balance is achieved (three-stream model). And finally, some additional pressure losses can be reflected in the jet pipe and/or final nozzle of the mixing chamber. As quoted in Watcher et al. ${ }^{[27]}$, in this type of model, physical effects rely on coefficients applied to a 'synthesized uniform thermodynamic profile' each time. Figure 5 illustrates this approach.

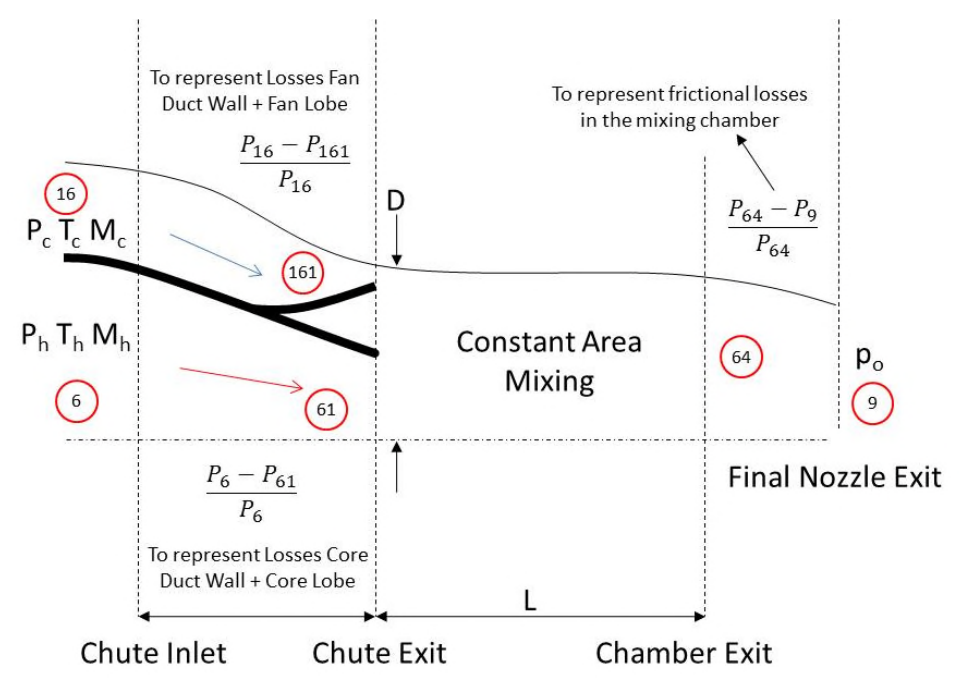

Figure 5 - Pressure loss representation in the mixing chamber

\section{Methodology}

In this work, partial mixing, based on the three-stream model, was introduced in a typical non-dimensional thermodynamic cycle analysis code developed in-house at Cranfield University in the UK, called TURBOMATCH ${ }^{[30][31][32][33]}$. This allowed studies with partial mixing to take place following a new modelling strategy that satisfies the following criteria;

1. Conservation of mass flow, energy and momentum across the system boundaries,

2. No work or heat transfer across the system boundaries,

3. Equal static pressure and a fixed hot flow inlet Mach number at the mixer entrance in order to determine the inlet flow area,

4. Percentage of mass flow which is mixed from each stream is the same, therefore mixing efficiency represents a measure of how much of each stream is allowed to mix,

5. Expansion of the mixed stream, and the unmixed hot and cold streams, occurs through their own separate nozzles,

6. Fixed inlet and outlet areas at off-design conditions.

As it can be seen in Figure 6, to implement this strategy in TURBOMATCH, a number of splitter and nozzle "bricks" were used as well as a mixer brick was used. The splitter brick is 
used to split the flow into two streams. These two streams will have the same flow characteristics (this includes but is not limited to static and total pressure, temperature and density) but will have different mass flow rates. The mixer brick is used to mix two streams with different flow characteristics and mass flow rates. The mixed stream is formed from a proportion of the core stream and a proportion of the bypass stream specified by these splitters. Typically they are both set to the level of mixing efficiency required. For example if the mixing efficiency is set at $75 \%$, then the proportions of both streams are set to 0.75 , and $75 \%$ of both streams mix in the mixed stream. The nozzle brick is used to calculate the thrust and the exit area for that particular stream. The nozzle brick will also consider if the nozzle is chocked. Three nozzle bricks were required in total, one for each of the three streams. This means each stream has its own exit area and thrust. These are then added at the end of the process to find out the required total nozzle exit area and the total produced thrust for all three nozzles. The area / thrust split between the streams is determined by the mixing efficiency that the mixed exhaust system. Higher mixing efficiency results in a larger fully mixed nozzle as more flow is directed to nozzle. With lower efficiencies more flow is diverted to the unmixed nozzles.

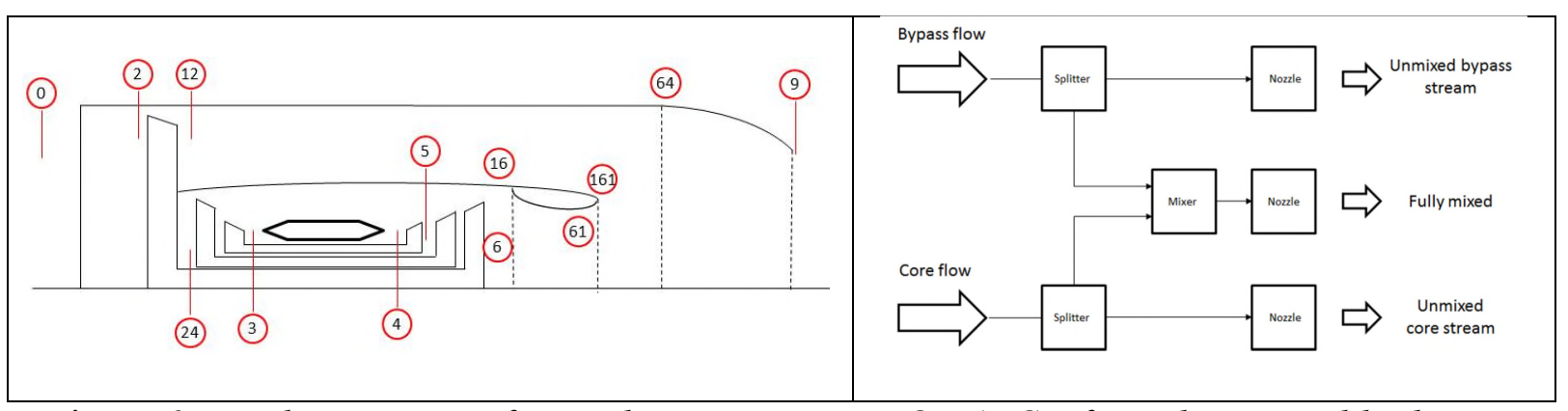

Figure 6 - Implementation of partial mixing in TURBOMATCH for a three-spool high-BPR turbofan

Calculations were performed in a computer with a Windows 64-bit operating system, and 3.6 $\mathrm{GHz}$ processor. Convergence of each cycle design point occurred in less than 10 seconds.

\subsection{Verification of the partial mixing modelling}

The verification of the modelling strategy to simulate partial mixing was conducted using data available in the public domain. This was done to see if the same trends were present with the current approach, compared to the analytical approach used in the literature. Two gas turbine models were created; the first model was set up as a representation of the RB211535E4 engine. This model is called hereafter as "Engine Model A". The second model is a representation of the RB211-524G/H engine, again based on public domain data. This model is called hereafter as "Engine Model B". These three-spool mixed turbofan engines were chosen as their theoretical trends could be compared against previous work done at Cranfield ${ }^{[31]}$. The known engine characteristics are shown below in Table 3 . These values have been identified in reference ${ }^{[1]}$. Unfortunately, not all the information on these engines is available in the public domain, and therefore certain parameters had to be assumed. These included the FPR, TET, component efficiencies and pressure losses. The assumptions that were made, used values which are considered reasonable for the expected technology level of these engines.

The mixing efficiency for both engines was set at $25 \%$. This value was chosen after consultation with industry experts. The engines were matched for SFC, thrust at cruise, and 
thrust at SLS. To find the optimum FPR for these engines, the FPR was varied, while maintaining fixed OPR and the power distribution between the IPC and HPC. Once the engines were matched, the mixer was removed, and the process was carried out again. This produced the optimum separate-jet configuration, which provided a baseline to compare against. With the baseline determined, the mixing efficiency of the mixed engine was varied parametrically to establish the performance trends of the authors' modelling strategy and compare against public domain data. The results of this verification are shown in the Figure 8. In that figure the results of the two engine models are compared against the data from Rayee et $\mathrm{al}^{[25]}$ and Frost ${ }^{[2]}$. This is further enhanced by Table 4. Due to lack of data a one to one comparison is not possible however one can compare the percentage of thrust reduction observed in those papers when looking at mixing efficiency.

Table 3 - Engine model performance characteristics for the verification of incomplete mixing modelling ${ }^{[1]}$

\begin{tabular}{lccc}
\hline Engine & Engine Model A & Engine Model B & Units \\
\hline SFC mid-cruise & 17.48 & 16.20 & $\mathrm{mg} / \mathrm{Ns}$ \\
Thrust cruise & 38.7 & 52.5 & $\mathrm{kN}$ \\
Thrust at SLA & 192 & 269.6 & $\mathrm{kN}$ \\
OPR & 28.0 & 34.5 & - \\
BPR & 4.3 & 4.1 & - \\
Fan diameter & 1.882 & 2.192 & $\mathrm{~m}$ \\
Mass flow rate & 522 & 738.5 & $\mathrm{~kg} / \mathrm{s}$ \\
\hline
\end{tabular}

\section{Evaluation}

This section explores the uninstalled performance of the two engine models previously mentioned. It assumes a free mixing process evolving in a constant area duct, and complete uniformity of each stream before expansion in the corresponding expansion nozzles.

\subsection{Comparison of numerical results against thermodynamic model}

A verification of the global performance trends was conducted to test the modelling strategy used to represent the mixing efficiency. This was essential to assure that using "splitting blocks" would produce accurate results when taking mixing efficiency into account. This strategy was already shown in Figure 6. The turbofan engine models used for this verification study were shown in Table 3. Pressure losses in these engine models were considered fixed, therefore the mixing efficiency is independent of the losses in this study.

After "Engine Model A" was matched with data in the public domain, the mixer was removed and the optimum separate-exhaust turbofan model was created to calculate the baseline thrust. Once the baseline thrust was established, the mixing efficiency of the mixedexhaust engine model was increased, first to $75 \%$ and then to $100 \%$. At each mixing efficiency level the FPR was used to vary the mixer inlet hot/cold stream pressure ratio. For each engine model the theoretical thrust gain was calculated by comparing the thrust achieved against the optimum thrust of the baseline configuration. The results of this parametric study are shown in Figure 7. The second engine model was also simulated in an identical manner. 
Please do not include headers and footers

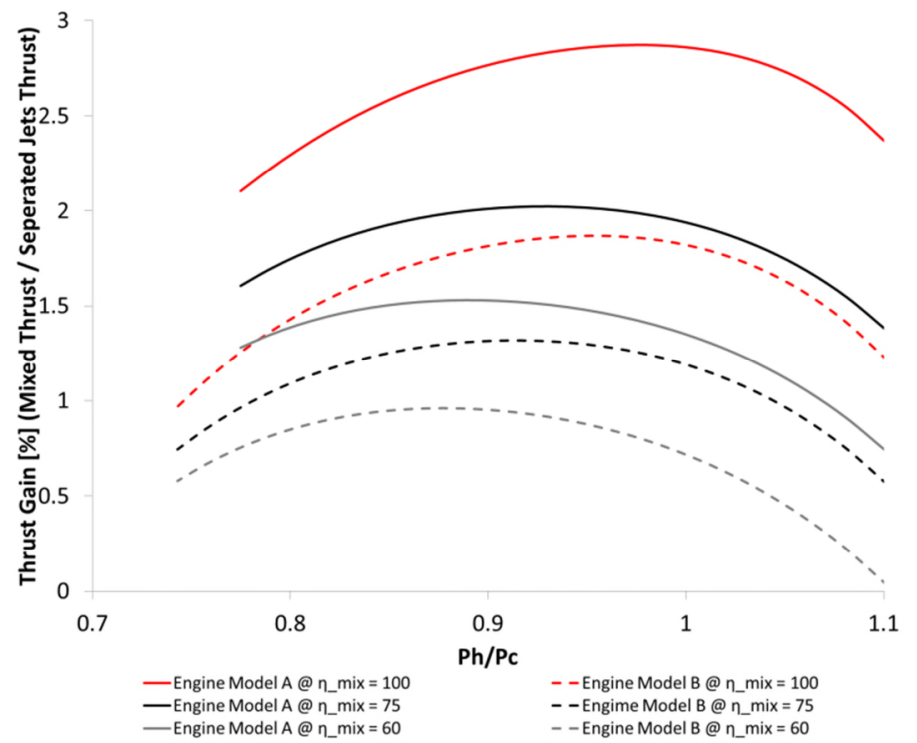

Figure 7 -Mixed nozzle cruise performance vs. mixing efficiency of "Engine Model A" and "Engine Model B" both at mixer entry Mach number $=0.5, T_{h} / T_{c} \approx 2$

When analysing these figures and comparing them against Figure 8, a similar general trend can be observed but also some differences emerge. The first difference is that the maximum value for thrust gain is different for both engine models. This is partly due to the effect of the BPR and the TR which were shown in Figure 1. The size (mass flow) of the engine seems to play a major part as there is only a small difference between "Engine Model A" and "Engine Model B" in terms of BPR and TR, however a significant difference in engine size.

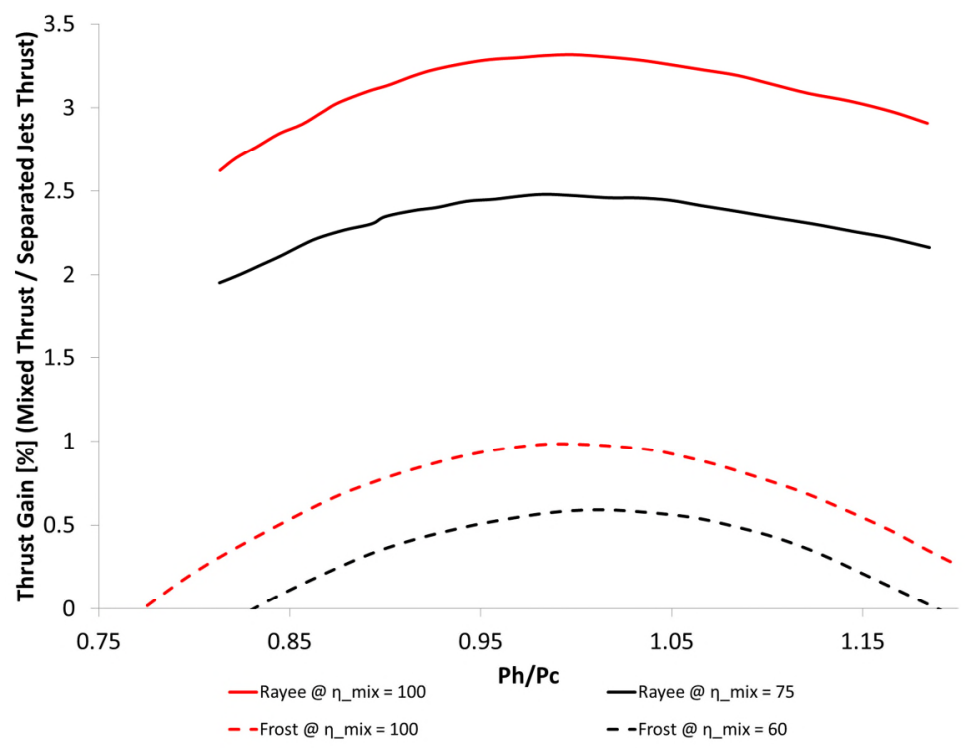

Figure 8-Analysis of the mixing efficiency at the mixing chamber inlet on the thrust gain achievable for a turbofan engine model of $B P R=5$, mixer core inlet Mach number $=0.4$, $T_{h} / T_{c}=3$ (adapted from Rayee et al ${ }^{[25]}$ ), $T_{h} / T_{c}=2.22, M_{h} / M_{c}=1.0, P_{m} / p_{0}=2.1, \quad(M a)_{m}=$ 0.475 (adapted from Frost ${ }^{[2]}$ )

The second difference is the location of the optimum thrust gain compared to $\mathrm{P}_{\mathrm{h}} / \mathrm{P}_{\mathrm{c}}$. In Figure 8 it can be seen that the optimum thrust gain is achieved when $\mathrm{P}_{\mathrm{h}} / \mathrm{P}_{\mathrm{c}}=1$. However, this is not the case for "Engine Model A" and "Engine Model B". It could be argued that the engine model analysed in Figure 8 was created using an analytical approach whereby flow 
characteristics at the inlet of the mixer could be set directly. Also the effect of inlet Mach number was not taken into account, as it was fixed at 0.4. The axial Mach number at the mixer inlet has an effect on the optimum mixer $\mathrm{P}_{\mathrm{h}} / \mathrm{P}_{\mathrm{c}}$ ratio as it was demonstrated by Guha ${ }^{[22]}$.

Table 4 -Comparing theoretical thrust gain from different engine models against Rayee et $a^{[25]}$, and Frost ${ }^{[2]}$

\begin{tabular}{lcccc}
\hline Engine & $\eta_{\text {mix }}=100$ & $\eta_{\text {mix }}=75$ & $\eta_{\text {mix }}=60$ & $\Delta[\%]$ \\
\hline Rayee $^{[25]}$ & 3.3 & 2.5 & - & $\approx 25$ \\
Frost $^{[2]}$ & 1.0 & - & 0.6 & $\approx 40$ \\
Engine Model A & 2.8 & 2.1 & - & $\approx 28$ \\
Engine Model A & 2.8 & - & 1.6 & $\approx 41$ \\
Engine Model B & 1.8 & 1.3 & - & $\approx 27$ \\
Engine Model B & 1.8 & - & 1.0 & $\approx 44$
\end{tabular}

The common trend that can be observed in the two figures and from Table 4 is that engine performance drops in a similar manner. This is despite the fact that the maximum value for thrust gain and the location of that value with respect to $P_{h} / P_{c}$ are different for all three engine models. Furthermore, when comparing the delta in thrust gain between the optimum values for $60 \%, 75 \%$ and $100 \%$ mixing efficiency respectively, it can be seen and calculated that there is a reduction of thrust gain of approximately equal to the reduction in mixing efficiency. This is consistent for all three engines.

\subsection{Mixing efficiency parametric study}

A parametric study was conducted to identify the effect of mixing efficiency on the available design space in regards to the mixer inlet characteristics. The main focus was on the mixer inlet total pressure ratio, which is directly controlled by the FPR. The study was conducted using the same engine models and methodology from the verification study. For this study a range of mixing efficiency was simulated at different inlet mixer pressure ratios. The mixing efficiency ranged from $10 \%$ to $100 \%$. The core Mach number at mixer entry chosen was 0.4 . The results for "Engine Model A" and "Engine Model B" are shown in Figure 9 (a) and (b) respectively. 
Please do not include headers and footers

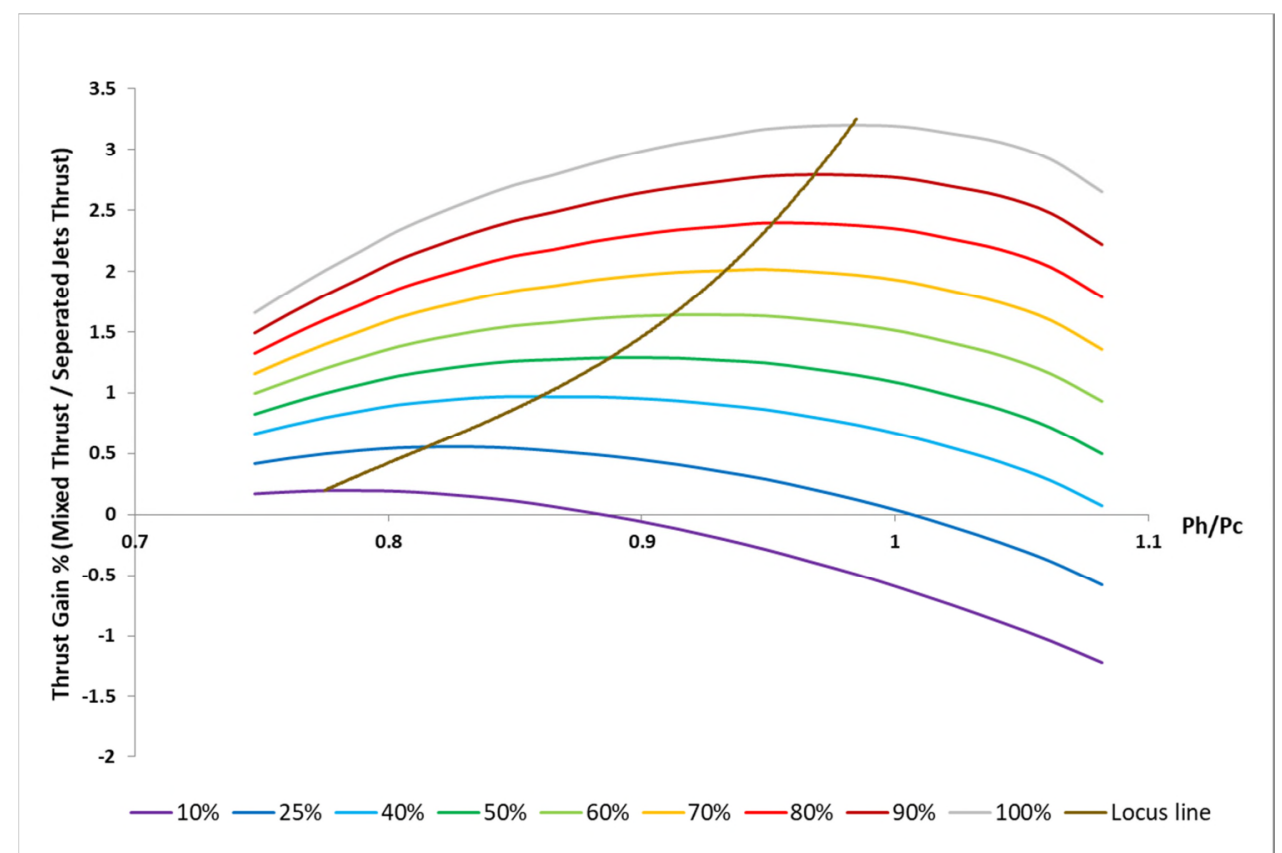

(a)

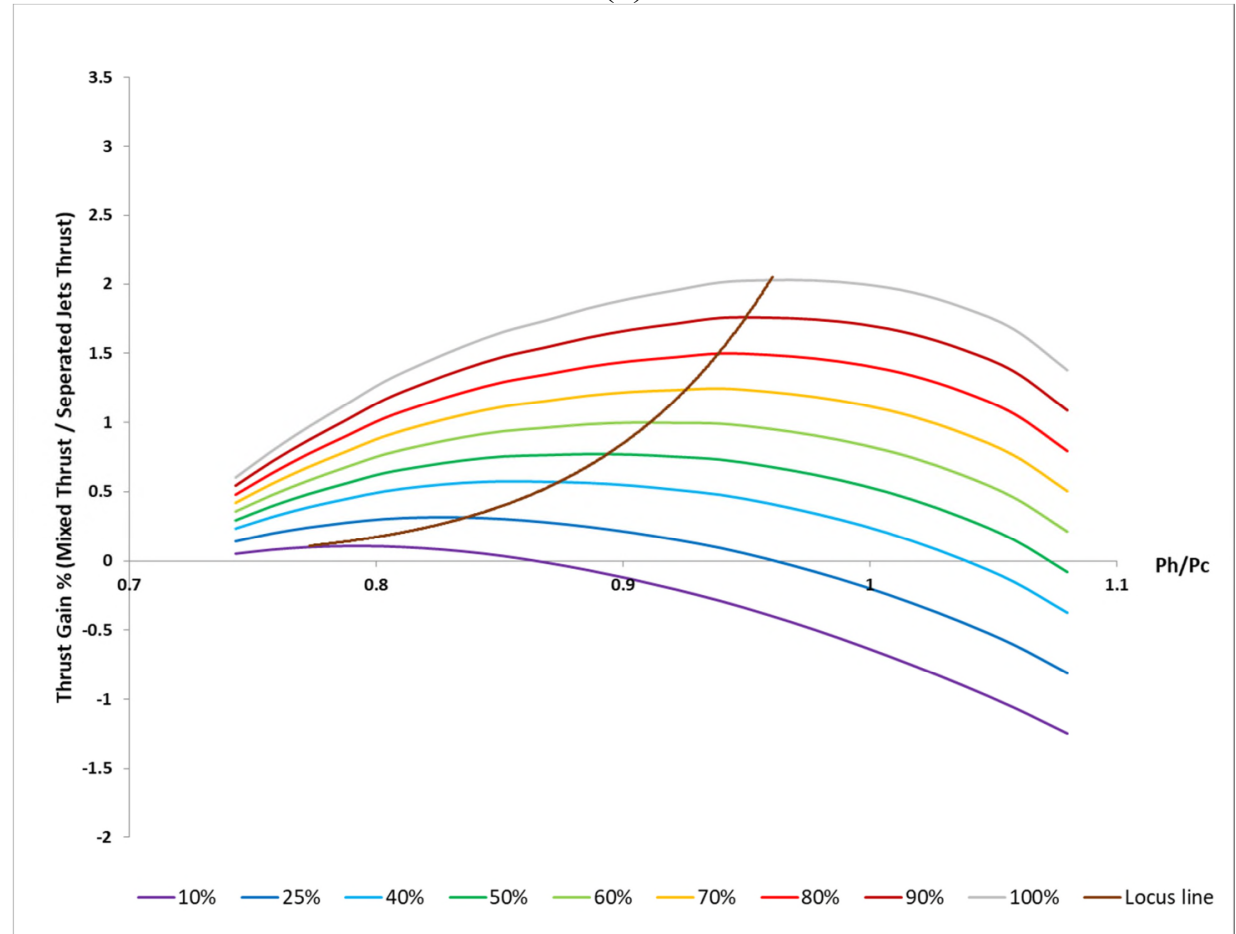

(b)

Figure 9-Effect of mixing efficiency on \% thrust gain for: (a) "Engine Model $A$ " $\left(T_{h} / T_{c} \approx\right.$ 2.4) and (b) "Engine Model B" $\left(T_{h} / T_{c} \approx 2.0\right)$, both with mixer core inlet Mach number $=$ 0.4

When examining these two figures the following observations can be made. The first is that the optimum total pressure ratio is very similar for both engine models at each level of mixing efficiency. However, the magnitudes of the theoretical thrust gain are substantially larger for "Engine Model A" than for "Engine Model B", especially at 100\% mixing efficiency. This cannot be attributed only to the small differences of TR, nor BPR as both engine models have similar values. The difference in potential thrust gain, given the fact that 
for each engine model the values of TET, OPR and Specific Thrust were fixed, should be linked to the size of each engine and their points of comparison.

The potential thrust gain that a mixed-exhaust engine can have is numerically associated with the reduction in FPR and LPT pressure ratios compared to a separate-jets engine with the same Specific Thrust. For a given turbofan, the optimum FPR relates to a certain amount of energy conveyed between the core and the by-pass flow. In a separate-exhaust turbofan this energy needs to be transferred through the LPT and the fan where some losses take place. However, for a mixed-exhaust turbofan some of the conveyed energy can be transferred through the mixer, increasing the transmission efficiency, and therefore reducing the LPT pressure ratio and the optimum FPR. The difference in magnitude between the optimum FPRs for both configurations (given the same Specific Thrust), will frame the potential thrust gain when mixer installation effects are not taken into account.

The reason for the reduction in thrust gain for lower specific thrust, like for "Engine Model B" with roughly the same BPR than "Engine Model A", should be investigated at their corresponding points of comparison. "Engine Model B" has about 40\% more inlet mass flow than the "Engine Model A"; roughly estimated through fan diameter; $2.192 \mathrm{~m}$ against $1.882 \mathrm{~m}^{[1]}$ respectively. A similar low Specific Thrust separate-jets engine as "Engine Model B" would be designed (considering the same scale thrust-fan diameter) with a low FPR; therefore the impact of reducing the LPT pressure ratio and FPR through mixing would be less pronounced.

These parametric results also show that even though the mixer inlet pressure ratio is the same in both engine models, the FPR op for "Engine Model A" is larger than for "Engine Model B", which is expected, given the bigger specific thrust of the first ${ }^{[22]}$. It was also numerically reproduced that the total pressure ratio at the mixer inlet, is strongly influenced by the FPR selection, as it is shown by the shape of the potential thrust gain curves.

Another important observation is that the optimum mixer inlet pressure ratio $\mathrm{P}_{\mathrm{t}_{\text {hot }}} / \mathrm{P}_{\mathrm{t}_{\text {cold }}}$ increases as the mixing efficiency increases. This change in optimum mixer inlet pressure ratio has been depicted by the 'locus line' in both figures. As the FPR is directly linked to the mixer inlet pressure ratio it can be seen that as the mixing efficiency increases the $\mathrm{FPR}_{\mathrm{op}}$ decreases (see Figure 10).

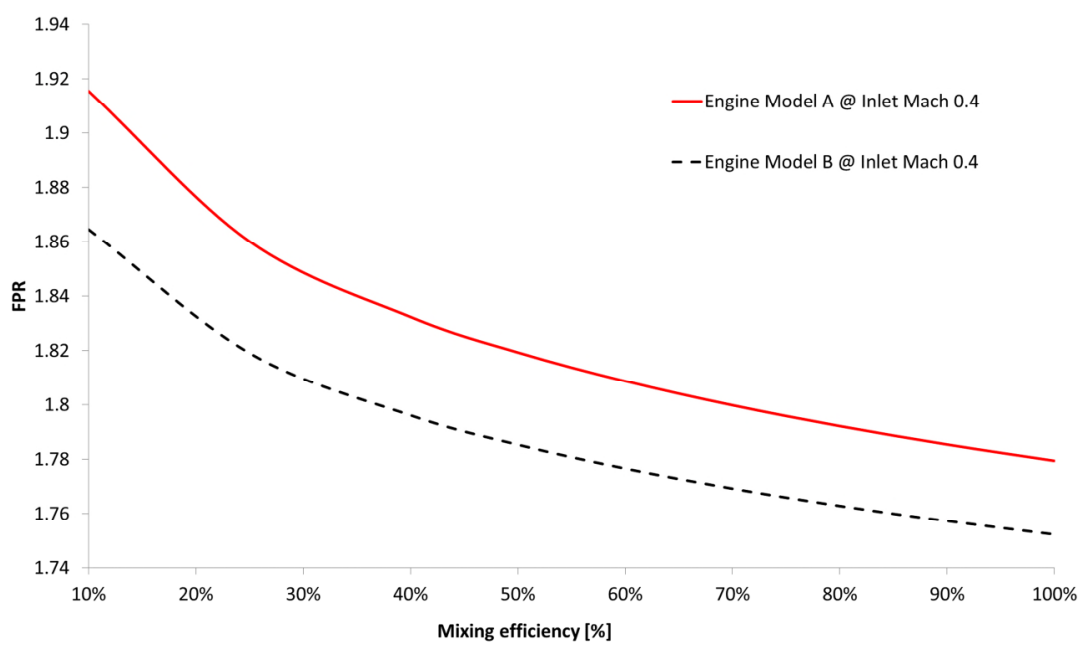


Figure 10- Effect of mixing efficiency on FRP in "Engine Model $A$ " $\left(T_{h} / T_{c} \approx 2.4\right)$ and "Engine Model B" $\left(T_{h} / T_{c} \approx 2.0\right)$, both with mixer core inlet Mach number $=0.4$

The reason for this is that the FPR is primarily determined by the conditions at which mixing occurs, and according to Guha ${ }^{[22]}$, the $\mathrm{FPR}_{\text {op }}$ is greatly influenced by the Specific Thrust (not the BPR) of a mixed-exhaust engine. In the same work, it was demonstrated that the Specific Thrust is a linear function of the mixing efficiency (equation 23 of ${ }^{[22]}$ ); therefore increasing mixing efficiency will have the same monotonic relationship with the optimum FPR.

\subsection{Mixer inlet Mach number parametric study}

The second parametric study conducted was on the mixer inlet Mach number of the hot stream. The reason for this parametric study was to gain a clearer understanding of the influence the mixer inlet Mach number has on the stability of the thermodynamic engine model. Since Hartmann ${ }^{[4]}$, selecting a value of around 0.4 for the mixing inlet Mach number has become a common convention at design point; however, it is important to understand the influence the mixer inlet Mach number has on inlet flow characteristic and the ratio of total pressures at the mixer inlet. Guha ${ }^{[22]}$, looked at the effect of mixer inlet Mach number on FPRop, he changes the mixer inlet Mach number from 0.2 to 0.6 . He only looked at this parameter very briefly but did not draw any substantial conclusions from the result. This study advances from the analysis of Mach number impact reported in Guha ${ }^{[22]}$.

For this study, the same engine models as in the previous parametric study were used. The engines were simulated using different inlet Mach numbers for the hot stream ranging from 0.1 to 0.5 . Furthermore, the engine models were also run over a mixing efficiency range from 10 to $100 \%$. It needs to be pointed out that the losses were fixed in this study as well. This means that the increased diameter of the mixer due to the lower Mach numbers did not affect the losses experienced in the mixer.

Figure 11, shows the relationship between the core Mach number at the mixer inlet versus the optimum mixer inlet total pressure ratio. The first observation is a confirmation that the numerical results for "Engine Model A" show the same trends as the analytical approach published by Guha ${ }^{[22]}$, which is shown as a black line. The second observation is that the optimum mixer inlet pressure ratio is different between the two engines but this is what is expected as Guha's engine is significantly smaller than "Engine Model A". Finally, numerical results are showing trend that suggest that for a given core Mach number the mixing efficiency has also an impact of the optimum mixer inlet total pressure. The lower the mixing efficiency, the curve for an optimum FPR is shifted in their level values and the signs of the slopes change. The first trend is expected as each mixing efficiency would readjust the level of energy required from the fan and core stream to hit a thrust target. The second are inherent from the assumptions of the three steam methodology, which automatically creates small anomalies in the final nozzle because the thrust is computed by a different process from that used for satisfying the final nozzle area and so the final nozzle area and gas conditions are not consistent with the thrust. In the iterative process to match the nozzle areas, the streams properties start numerically to deviate. 
Please do not include headers and footers

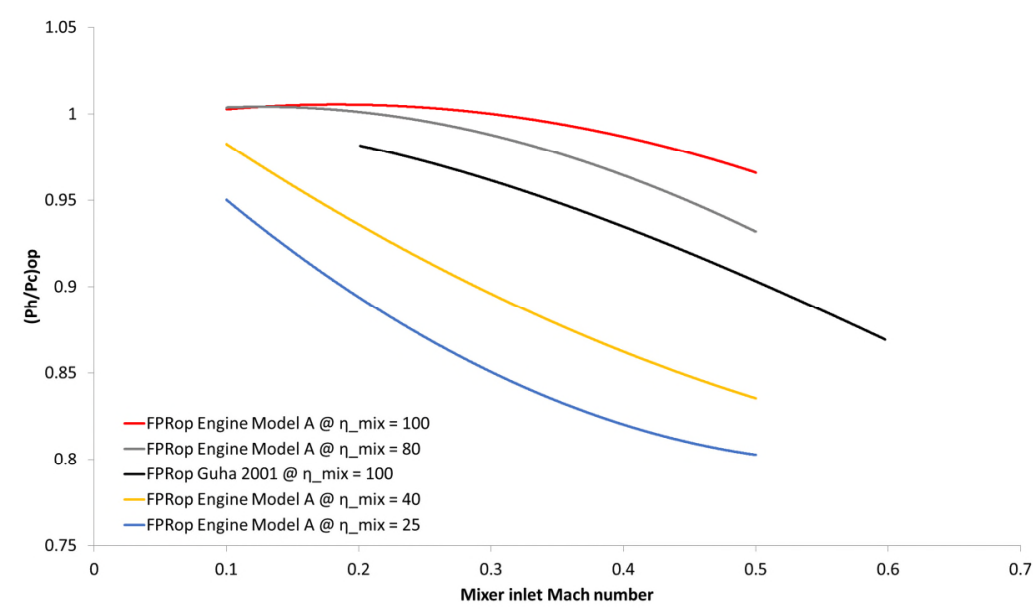

Figure 11 - Effect of mixer core inlet Mach number on optimum mixer inlet pressure ratio for "Engine Model A" at mixing efficiency of 100\%, 80\%, 40\% and 25\%

If in Figure 11 the numerical results obtained for "Engine Model A" were expanded to include all mixing efficiencies, Figure 12 would be obtained. As expected from Guha ${ }^{[2]}$, the optimum mixer inlet pressure ratio is strongly linked with the design Mach number of the core stream. It can also be observed from this figure that increasing mixing efficiency changes the optimum total pressure ratio at the mixer inlet. It is interesting to note that for the lowest values of Mach number, optimum values are already close to one, from $60 \%$ mixing efficiency to $100 \%$. However, going to higher inlet Mach numbers, say from 0.4 to 0.5 , the total pressure ratio at the mixer inlet is at $\mathrm{P}_{\mathrm{h}} / \mathrm{P}_{\mathrm{c}}=0.95$. This seems to be slightly different to what has been suggested by Millhouse ${ }^{[34]}$ and Guha ${ }^{[22]}$, who recommended selecting design ratios of $\mathrm{P}_{\mathrm{t}_{\text {cold }}} / \mathrm{P}_{\mathrm{t}_{\text {hot }}}$ (the inverse ratio than the convention used in this paper) between 0.95 and 1 (which would be between 1.05 and 1 in the present work) for small BPR engines. Guha ${ }^{[22]}$ in his numerical experiments used a mixer core inlet Mach number of 0.3; meanwhile Millhouse $^{[34]}$ did not explicitly specify this value.

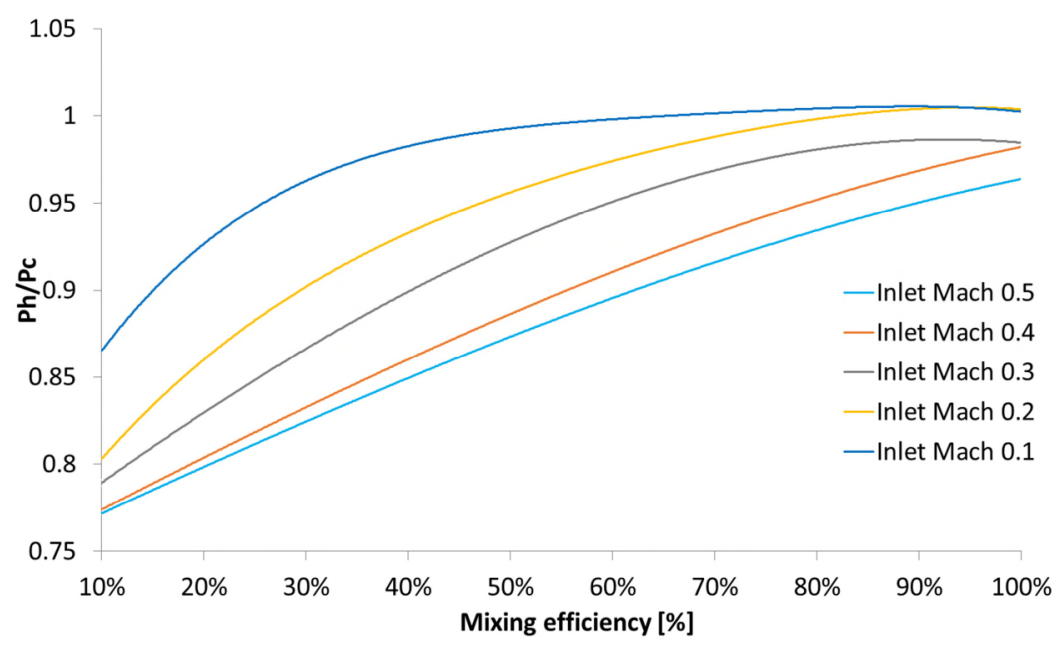

Figure 12 - Effect of mixer core inlet Mach number and mixing efficiency on mixer ratio of total pressures for "Engine Model A"

It can be inferred that following the methodology proposed, the ratio of the total pressures at the mixer inlet is dependent on the mixer inlet Mach number as well as the mixer 
Please do not include headers and footers

effectiveness. Furthermore, at design point for a fixed core inlet Mach number the mixer inlet pressure ratio increases significantly with the increase in mixing efficiency.

The next case examines the effect of core inlet Mach number on thrust gain for "Engine Model A" for a constant mixing efficiency. Figure 13 and Figure 14 illustrate the effect of the core inlet Mach number on the potential thrust gain for $25 \%$ and $100 \%$ mixing efficiency respectively.

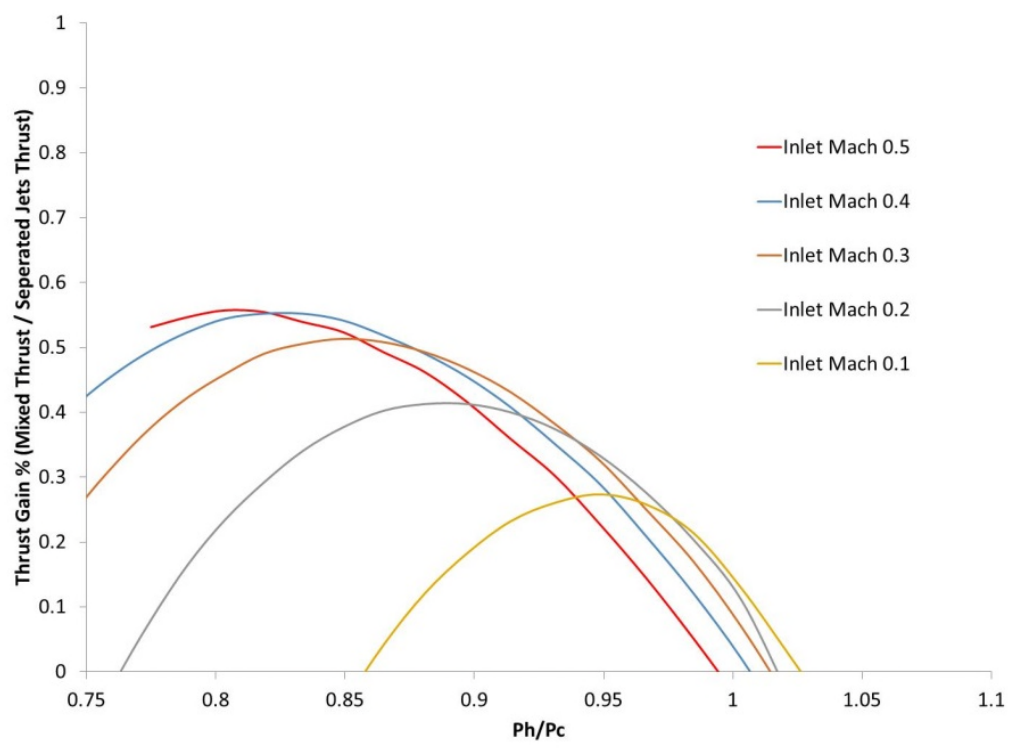

Figure 13 - Effect of mixer core inlet Mach number and pressure ratio on \% thrust gain for "Engine Model A" (mixing efficieny 25\%)

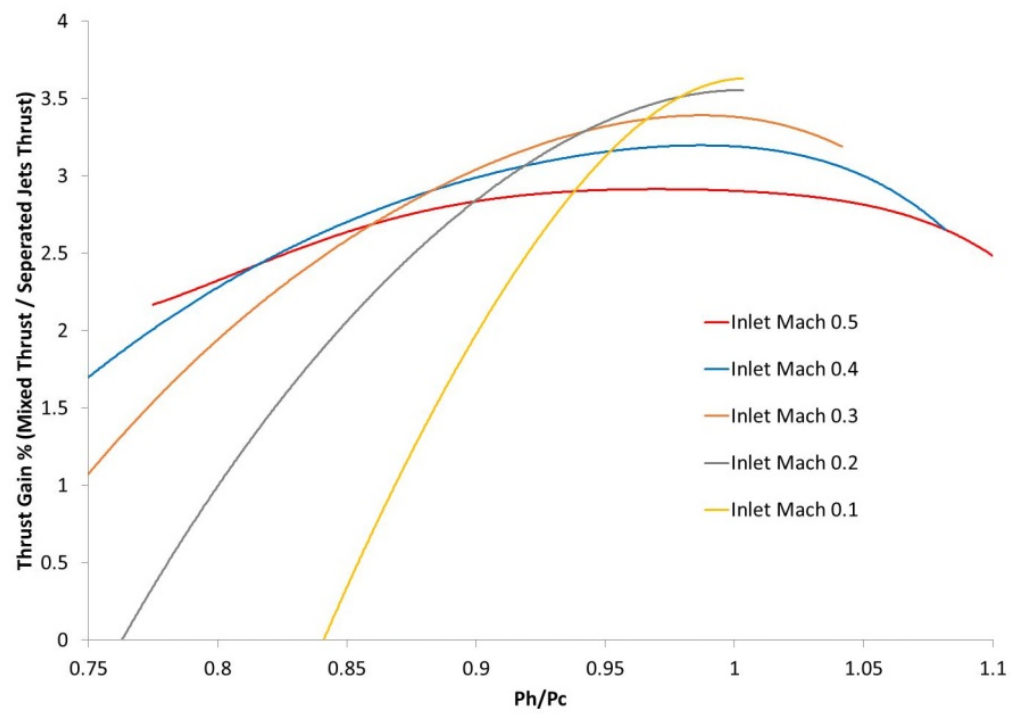

Figure 14 - Effect of mixer core inlet Mach number and pressure ratio on \% thrust gain for "Engine Model A" (mixing efficieny 100\%)

Figure 13 shows no results for a core inlet Mach number of 0.5 with total pressure ratio at the mixer inlet lower than 0.77 . This is an outcome of the modelling methodology selected and 
the internal structure of the software, specifically the "mixer block" algorithm. This block was developed for guessing the second Mach number for a specific set of constrains in the ratio of total pressures. Therefore, each time a value for the axial Mach number at the core mixer inlet is selected, it results in the calculation of a static pressure for a given total pressure. This static pressure will be the same in the cold side which will result in a Mach number for that inlet. When going to lower mixer inlet pressure ratios, the cold section total pressure is significantly higher than the hot section. Thus using an inlet Mach number of 0.5 at the hot mixer inlet, will result in a significantly higher Mach number at the cold mixer inlet. Ratios of total pressure at the mixer entry below 0.77 result in supersonic values for the Mach number at the cold inlet. Therefore, any results beyond that point are considered nonviable.

Figure 13 also shows that the available design space seems to increase when going to higher Mach numbers. The positive thrust gain seems to be restricted over a narrow range of pressure ratios for an inlet Mach number of 0.1. However, the range of pressure ratios resulting in a thrust gain increases substantially with inlet Mach number. It can also be seen that the maximum thrust gain achievable at the inlet Mach number of 0.4 and 0.5 is very similar.

When analysing Figure 14, different observations can be made compared to Figure 13. The first concerns the higher ratios of total pressure at the mixer inlet. It can be observed that there is a specific upper limit to the mixer inlet pressure ratio for each inlet Mach number. When the Mach number is lower than 0.5, this reduces the maximum achievable value for mixer inlet pressure ratio. The reason for this is that at that point the static pressure of the mixer hot inlet is too close or exceeds the total pressure of the mixer cold inlet. Therefore, no mixing can take place and the thermodynamic cycle simulation software cannot produce a viable engine.

It can be said that the strategy for modelling three separate streams in the mixer proposed in this work, leads to certain considerations for the selection of the mixer core inlet Mach number which can be summarized as follows. When assuming equal static pressures for both streams at the mixing block inlet, the flow momentum derived from the conservation of momentum in the mixer, is expressed in terms of flow Mach number. Therefore, finding a suitable Mach number at the exit of the mixing block requires an appropriated selection of the inlet Mach number of only one stream. This selection is heavily affected by the amount of mixing allowed, i.e. mixing efficiency represented by mass flow split.

Despite the limitations of the methodology selected, results as the ones illustrated in Figure 15 can be obtained. Figure 15 clearly presents the effect of mixing efficiency on the theoretical uninstalled thrust gain. The trend presents a fairly linear fashion with the thrust gain, increasing with mixing efficiency. The mixer core inlet Mach number affects the slope of the lines. As the mixer core inlet Mach number increases, the slope decreases. Additionally, moving towards the separate-jets case, the effect of increasing mixer core inlet Mach number is positive regarding thrust generation. This is because greater mixer core inlet Mach numbers lead to greater $\mathrm{FPR}_{\mathrm{op}}$ which resembles the separate-jets case. Another interesting observation is that the point where the slope of the lines begins to change at the low mixing efficiency value. After that point, lower core inlet Mach number lines present a steeper slope at low value of mixing efficiency and due to the fact that their thrust gain was lower at design point, they intersect at a specific value of mixing efficiency. At higher mixing 
efficiency the increase in mixer inlet Mach number results in a negative effect on the thrust gain.

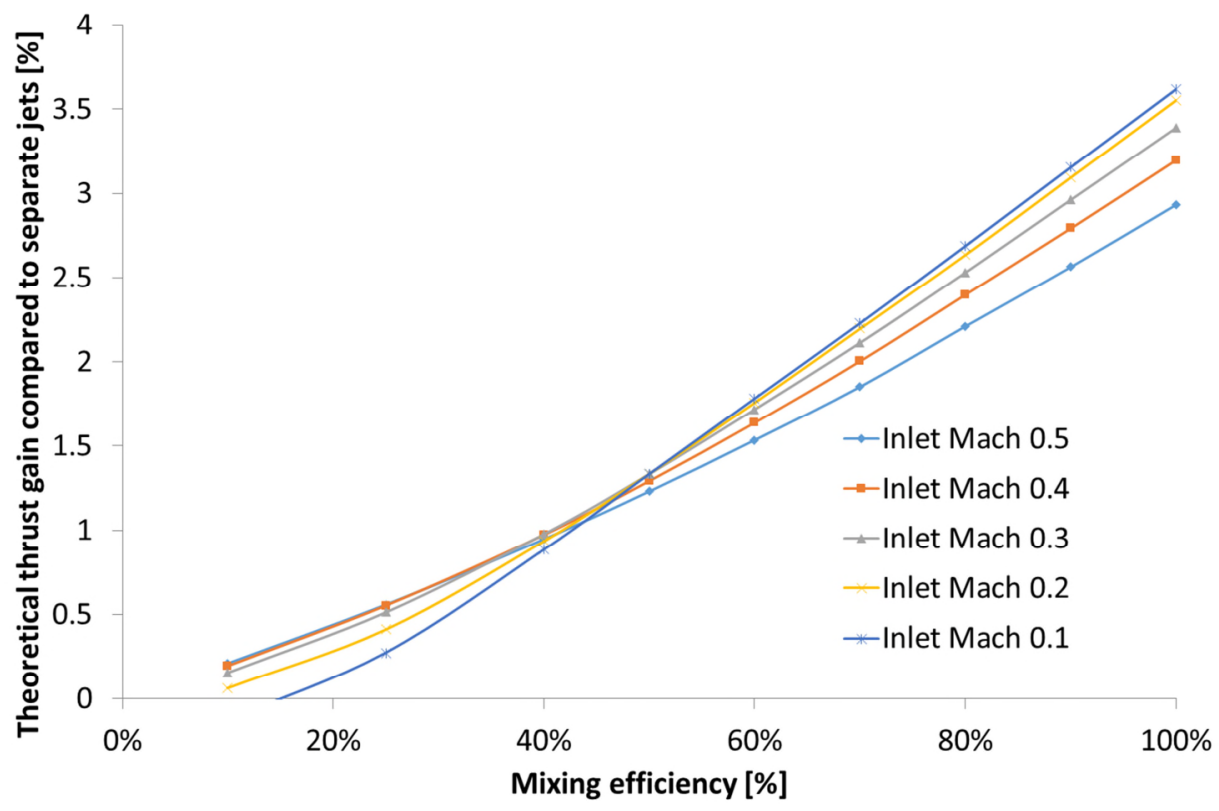

Figure 15 - Effect of mixer core inlet mach number and mixing efficiency on \% theoretical thrust gain for "Engine Model A"

From Sanghi et al. ${ }^{[24]}$, Eq. 3 can be defined as follows;

$$
M_{c}=\left(\frac{2}{\gamma_{c}-1}\left\{\left[\frac{P_{c}}{P_{h}}\left(1+\frac{\gamma_{h o t}-1}{2} M_{h}^{2}\right)^{\frac{\gamma_{h}}{\gamma_{h}-1}}\right]^{\frac{\gamma_{c}-1}{\gamma_{c}}}-1\right\}\right)^{\frac{1}{2}}
$$

It can be seen from Eq.3 that at a prescribed core (hot) inlet Mach number, bypass (cold) inlet Mach number will increase with the ratio of total pressures. This formulation allows calculating any of the three parameters, given two of them satisfy static pressure equality. The parametric work presented in this study suggests that a fourth parameter (i.e. the mixing efficiency) needs to be considered as well. This is because the choice of mixing can influence the optimum engine configuration significantly. Therefore, it is essential that the mixing efficiency should be included in the preliminary design-point performance calculations of BPR turbofan engines.

\section{Summary and Conclusions}

Parametric studies were conducted for two turbofan engine models with mixed flow and high BPR, to provide an understanding of the interdependence of two parameters: the mixing efficiency and the Mach number at the mixer inlet. Results of the numerical experiments showed that for the methodology followed, the design space is significantly influenced by the relationship between these two parameters.

With the goal of achieving the highest possible theoretical uninstalled thrust gain, it was found that without taking losses into account the choice of the Mach number at the mixer 
inlet is heavily influenced by the mixing efficiency and vice versa. More specifically, it would be more beneficial with regards to the theoretical thrust gain to choose a relatively higher mixer inlet Mach number at lower mixer effectiveness and a lower mixer inlet Mach number at higher mixer effectiveness. The numerical results of this study do not take into account the effects on mixer size, weight and design complexity to achieve various levels of mixing efficiency.

The selection of the Mach numbers at the mixer inlet influences the selection of the optimum FPR through the dependent parameter of mixer total pressures ratio; however the level of mixing efficiency, or the fraction by which each stream mixes, also plays a significant part in determining the optimum value for FPR, as that is directly linked to the mixer inlet pressure ratio and specific thrust.

The optimum value of total pressure ratio at the mixer inlet $\left(\mathrm{P}_{\mathrm{h}} / \mathrm{P}_{\mathrm{c}}\right)$, would lay between the values of 1 to 1.05 , only for $100 \%$ mixing efficiency and moderate inlet mixer Mach numbers. Following the methodology presented in this article, the maximum theoretical uninstalled thrust gain depends not only on the optimum level of Mach number of each stream, but also of the percentage of mass flow which could be mixed from each stream (mixer effectiveness).

It can also be concluded that the engine size influences the potential thrust gain available for the mixed-exhaust engine. However, this influences the $\mathrm{FPR}_{\mathrm{op}}$ and not the ratio of total pressures at the mixer inlet. Furthermore, the mixing efficiency plays a significant part in determining the optimum value for FPR as that is directly linked to the total pressure ratio and specific thrust.

It can be concluded that the thermodynamic performance of an engine cycle with a mixed exhaust should be derived on the basis of not only by the parameters which are most conventionally used, such as FPR, BPR, OPR and TR, but also by the selection of the Mach numbers at the mixer entry and the mixer effectiveness.

\section{Acknowledgement}

The authors would like to thank William Camilleri, Anthony Jackson and Andrew Rolt for their useful input in this research effort.

\section{References}

[1] Daley, M. (2010), “Jane’s Aero-Engines”, Issue 28, IHS Jane’s, IHS Global Limited, Great Britain.

[2] Frost, T. H. (1966), "Practical bypass mixing systems for fan jet aero engine," The Aeronautical Quarterly, May, pp. 141.

[3] Pearson, H. (1962), "Mixing of exhaust and bypass flow in a bypass engine," Journal of Royal Aeronautical Society, Vol. 66, pp. 528.

[4] Hartmann, A. (1968), "Theory and test of flow mixing for turbofan engines." Journal of Aircraft, Vol. 5, No. 6, pp. 522. 
Please do not include headers and footers

[5] Holmes, M., (1964), “An Investigation Into Mixing Between By-pass Air and Turbine Exhaust Gases - Part 1", Ministry of Aviation, National Gas Turbine Establishment, England, N.G.T.E. Report. No. R. 261.

[6] Holmes, M., (1964), “An Investigation Into Mixing Between By-pass Air and Turbine Exhaust Gases - Part 2", Ministry of Aviation, National Gas Turbine Establishment, England, N.G.T.E. Report. No. R. 262.

[7] Holmes, M., (1964), “An Investigation Into Mixing Between By-pass Air and Turbine Exhaust Gases - Part 3", Ministry of Aviation, National Gas Turbine Establishment, England, N.G.T.E. Report. No. R. 263.

[8] Holmes, M., (1965), “An Investigation Into Mixing Between By-pass Air and Turbine Exhaust Gases - Part 4”, Ministry of Aviation, National Gas Turbine Establishment, England, N.G.T.E. Report. No. R. 277.

[9] Leitham, J. J., Kulik, R. A., Weinstein, H., (1969), "turbulence in the mixing region between ducted coaxial streams", NASA, July, 1969.

[10] Ghia, K. N., Torda, T. P., Lavan, Z., (1970), “Turbulent mixing in the initial region of heterogeneous axisymmetric coaxial confined jets", NASA, May, 1970.

[11] Kuchar, A.P., Chamberlin, R., (1980), "Scale model performance test investigation of exhaust system mixers for an energy efficient engine (E3) propulsion system”, AIAA80-0229, AIAA, New York

[12] Cullom,R.R., Bobula, G.A. and Burkardt, L.A. (1981), "Mixing efficiency test of an exhaust gas mixer in a high bypass turbofan at altitude", NASA TM 82663, NASA, Cleveland, $\mathrm{OH}$.

[13] Rowe, K. Kuchar, A.P., (1982), "Scaled mixer performance report" NASA CR 167947, NASA, Cleveland, OH.

[14] Oates, G. C., (1985) "Performance estimation for turbofans with and without mixers", Journal of Propulsion and Power, Vol. 1, No. 3, pp. 252-256.

[15] Barber, T., Moore, G.C., Blatt, J.R., (1988), "Turbofan forced mixer lobe flow modelling", NASA, Washington

[16] Babbit, R.R., Cohn, J.A. and Fleming, K.J. (1991), “Advance high bypass mixed-flow exhaust system design study", AIAA-91-2242, AIAA, Washington, DC.

[17] Booher, M.E., Kwon, O., Barta, A.B., (1993), "Development of an advanced exhaust mixer for a high bypass ratio turbofan engine", AIAA, Washington, DC.

[18] Tsui,Y., Wu, P.W., (1996),'Investigation of the mixing flow structure in multilobe mixers", AIAA Journal, vol 34, no. 7, pp. 1386-1391 
Please do not include headers and footers

[19] Barta, A.B., Vittal, B.R. and Dalton, W.N. (1997), "Experimental verification of the exhaust mixing process in turbofan engines", AIAA, Washington

[20] Mundt, Ch., Lieser, J., (2001), "Performance improvement of propulsion systems by optimization of the mixing efficiency and pressure loss of forced mixers", $8^{\text {th }}$ European Propulsion Forum, 26-28 March 2001, Nottingham, United Kingdom.

[21] Sheng, Zhi-quiang, (2017) "Jet mixing of lobed nozzles with spoilers located at lobe peaks", Applied Thermal Engineering, Vol 119, pp 165-175.

[22] Guha, A. (2001), "Optimum fan pressure ratio for bypass engines with separate or mixed exhaust streams", Journal of Power and Propulsion, vol. 17, no. 5, pp. 1117.

[23] Millhouse PT, Kramer SC, King PI, Mykytka EF. (2000) "Identifying optimal fan compressor pressure ratios for the mixed-stream turbofan engine". Journal of Power and Propulsion. Vol 16, No 1, February; p. 79-86.

[24] Sanghi V, Lakshmanan BK. (2002) "Optimum mixing of core and bypass streams in high-bypass civil turbofan”. Journal of Power and Propulsion, Vol 18, No 4, JulyAugust, p. 907-911

[25] Rayee, T., Verstraete, D. and Hendrick, P. (2008), "Development of a mixer model to compare mixed and unmixed HBPR turbofans", AIAA 2008-4963/44th AIAA/ASME/SAE/ASEE Joint Propulsion Conference \& Exhibit, 21-23 July 2008, Harftord, CT

[26] Walsh, P. and Fletcher, P. (2004), "Gas turbine performance", 2nd ed, Blackwell Science Ltd, Great Britain.

[27] Wachter,J. and Kopf, F.(2009), “Advance exhaust performance modelling of mixed turbofan engines - Less is more", Proceedings of the 2009 ASME Turbo Expo, Vol.1, 8-12 June 2009, Orlando, FL,pp.155-164.

[28] Vivek Sanghi and Lakshmanan, B.K. (2002), "Optimum Mixing of Core and Bypass Streams in High-Bypass Civil Turbofan", Journal of Propulsion and Power, Vol 18, No.4, July-August 2002.

[29] Kuchar, A.P. and Chamberlin, R. (1985), "Subscale-model and full-scale engine mixed-flow exhaust system performance comparison", Journal of Aircraft, vol. 22, no. 11 , pp. $950-955$

[30] MacMillan, W.L. (1974), "Development of a modular-type computer program for the calculation of gas turbine off-design performance ( $\mathrm{PhD}$ Thesis)", Cranfield University, Cranfield Press, UK 
Please do not include headers and footers

[31] Van den Hout, F. (1991), "Gas turbine performance simulation improvements to the Turbomatch scheme", Cranfield University, Cranfield Press, UK.

[32] Palmer, J. (1999), "The Turbomatch scheme for aero/industrial gas turbine engine design point/off design performance calculation", (unpublished), Cranfield University, UK

[33] Igie, U., Diez-Gonzalez, P., Giraud, A. Minervino, O., (2016), "Evaluating gas turbine performance using machine-generated data: Quantifying degradation and impacts of compressor washing”, Journal of Engineering for Gas Turbines and Power, Vol 138, Issue 12

[34] Millhouse, P.T., Kramer,S.C., King, P.I. and Mykytka, E.F. (2000), "Identifying optimal fan compressor pressure ratios for the mixed-stream turbofan engine", Journal of Propulsion and Power, Vol 16, No 1, pp. 79-86. 
2019-03-02

Effect of mixing Mach number and mixing efficiency on the preliminary cycle design of mixed high-BPR turbofans

Cleton, Bjorn

Elsevier

Cleton B, Anselmi E, Pellegrini A, et al., Effect of mixing Mach number and mixing efficiency on the preliminary cycle design of mixed high-BPR turbofans, Thermal Science and Engineering Progress, Volume 10, May 2019, pp. 299-308 https://doi.org/10.1016/j.tsep.2019.03.001

Downloaded from Cranfield Library Services E-Repository 